\title{
The acquisition of articles in child second language English: fluctuation, transfer or both?
}

\author{
Tatiana Zdorenko and Johanne Paradis \\ University of Alberta
}

Received October 2006; revised July 2007; accepted July 2007

The data for this study consisted of a longitudinal corpus of narratives from 17 English second language (L2) children, mean age of $5 ; 4$ years at the outset, with first languages (L1s) that do not have definite/indefinite articles (Chinese, Korean and Japanese) and L1s that do have article systems (Spanish, Romanian and Arabic). We examined these children's acquisition of articles in order to determine the role of L1 transfer and, in so doing, test the Fluctuation Hypothesis, and also to compare our findings to those from research on adult L2 learners. Three tendencies were found over two years: (1) All children substituted the for $a$ in indefinite specific contexts (i.e. showed fluctuation) regardless of L1 background; (2) all children were more accurate with use of the in definite contexts than with $a$ in indefinite contexts, regardless of L1 background; and (3) children with [-article] L1s had more omitted articles as error forms than children with [ + article] L1s, but only at the early stages of acquisition. Overall, L1 influence in the children's developmental patterns and rates of article acquisition was limited. Child L2 learners converged on the target system faster than prior reports have indicated for adult L2 learners, even when their L1s lack articles. Thus, we conclude that fluctuation is a developmental process that overrides transfer in child L2 acquisition of English articles, in contrast to what has been reported for adult L2 learners.

Keywords: child L2, English articles, fluctuation hypothesis, L1 transfer, second language acquisition

Address for correspondence: Tatiana Zdorenko, Department of Linguistics, University of Alberta, Edmonton, AB T6G 2E7, Canada; email: zdorenko@ualberta.ca 


\section{Introduction}

There has been a substantial amount of research demonstrating that the acquisition of the English system of determiners is difficult for learners of English as a second language (L2) (Huebner, 1985; Master, 1987; Parrish, 1987; Thomas, 1989; Murphy, 1997; Wakabayashi, 1997; Robertson, 2000; Lu, 2001; Trademan, 2002; Ionin and Wexler, 2003; White, 2003; Ionin et al., 2004; Lardiere, 2004; Hawkins et al., 2006; Snape et al., 2006; Ionin et al., in press). L2 learners of English often have persistent difficulty in the use of determiners until very late stages of acquisition, or do not ever reach native-like levels of performance. Studies that include comparisons of L2 learners from first-language (L1) backgrounds with and without article systems suggest that L1 transfer most likely plays a role in L2 learners' acquisition of English articles (Master, 1987; Murphy, 1997; Wakabayashi, 1997; Trademan, 2002; Hawkins et al., 2006; Snape et al., 2006; Ionin et al., in press). A recent and influential proposal put forward by Ionin and colleagues - the Fluctuation Hypothesis - makes specific predictions for the development of the English article system, and its most recent formulation takes L1 background into account (Ionin and Wexler, 2003; Ionin et al., 2004; Ionin et al., in press). A primary aim of this study was to test the predictions of the Fluctuation Hypothesis in particular, within the role of L1 transfer more generally.

Previous studies on the acquisition of L2 English have examined adult learners, often using cross-sectional designs based on level of proficiency attained to infer developmental change. Existing longitudinal studies of child L2 learners of English have been focused on investigating the children's acquisition of English verbal morphology (e.g. Lakshmanan, 1995; Haznedar, 2001). Dulay and Burt (1974) investigated the order of the acquisition of English morphemes in a cross-sectional study with Spanish L1 and Chinese L1 children. Articles were included in the list of morphemes investigated, but the authors did not analyse differences in accuracy rates based on L1 background, nor did they provide details on article choice, e.g. definite vs. indefinite, according to semantic/pragmatic context. Therefore, article acquisition in child learners of English has not yet been fully investigated, and certainly not with the aim of testing the predictions of the Fluctuation Hypothesis. Child L2 acquisition is a good testing ground for investigating structures that are problematic for all learners of a language, because it enables us to determine whether difficulties with 
a target structure are inherent in the process of learning that structure, rather than stemming from cognitive immaturity (i.e. L1 acquisition), on the one hand, or age-based limitations for native-like attainment (i.e. adult L2 acquisition), on the other (compare Schwartz, 2004). The present study reports longitudinal data from child learners of English, with both [+article] and [-article] L1s. We examined these children's acquisition of articles in order to determine the role of L1 transfer, and in so doing test the Fluctuation Hypothesis, and also to compare our findings to those from research on adult L2 learners. It will be argued that child L2 acquisition patterns and rates display some unique properties from those of their adult counterparts, in particular with respect to the role of the L1.

\section{Article semantics}

We adopt Ionin's (2003) and Ionin et al.'s (2004) analysis of definiteness and specificity as the semantic contrasts that can be encoded in two-article systems. This distinction is important in our analysis of article use in child L2 learners of English and in the discussion of the explanation of article misuse put forward in Ionin et al. (2004), namely the Fluctuation Hypothesis. Definitions of definiteness and specificity (Ionin et al., 2004: 5) are given below:

1) Definiteness and specificity: informal definitions:

If a Determiner Phrase (DP) of the form [D NP] is ...

a. $[+$ definite $]$, then the speaker and hearer presuppose the existence of a unique individual in the set denoted by the NP.

b. [+specific], then the speaker intends to refer to a unique individual in the set denoted by the NP and considers this individual to possess some noteworthy property.

While English marks definiteness in its article system, languages such as Samoan (Lyons, 1999; Ionin et al., 2004) mark specificity. In other words, English distinguishes between definite and indefinite nouns, while Samoan distinguishes between specific and non-specific nouns. Ionin et al. (2004: 12) assume that article systems in languages with two articles encode definiteness or specificity, but not both, and that article choice is governed by a binary parameter:

2) The Article Choice Parameter (for two-article languages): A language that has two articles distinguishes them as follows:

- The Definiteness Setting: Articles are distinguished on the basis of definiteness.

- The Specificity Setting: Articles are distinguished on the basis of specificity. 
Under this view, English has the first setting of the Article Choice Parameter and uses the with [ + definite] nouns and $a$ with [ - definite] nouns, regardless of whether nouns are specific or not. This is illustrated in example (3) taken from Ionin et al. (2004: 8).

3) a. I'd like to talk to the winner of today's race - she is my best friend!

b. I'd like to talk to the winner of today's race - whoever that is; I'm writing a story about this race for the newspaper.

In English, a definite noun can refer to a specific individual who possesses a noteworthy property, as in (3a), or to a non-specific individual, as in (3b). Thus, Ionin et al. (2004) conclude that the definiteness distinction encoded in the English article system is independent of the specificity distinction.

\section{Articles in L2 acquisition}

In the course of acquisition, L2 learners of English have been documented to omit articles in both definite and indefinite contexts, and to misuse them, that is substituting one in the context of another (e.g. Huebner, 1985; Master, 1987; Parrish, 1987; Thomas, 1989; Murphy, 1997; Robertson, 2000; Lu, 2001). In their recent research on this topic, Ionin and colleagues developed an explanation for the inappropriate use of articles in L2 English. On the basis of the Article Choice Parameter given in (2), Ionin et al. (2004: 16) put forward a parameter-setting account to explain the variability in L2 learners' productions of articles, the Fluctuation Hypothesis (henceforth, FH):

4) The Fluctuation Hypothesis:

- L2 learners have full access to Universal Grammar (UG) principles and parameter-settings.

- L2 learners fluctuate between different parameter-settings until the input leads them to set the parameter to the appropriate value.

Under the FH, L2 English learners are predicted to fluctuate between the two settings of the Article Choice Parameter until they are exposed to sufficient input to set the parameter correctly. Ionin et al. (2004) analysed article use in 30 L1 Russian and 40 L1 Korean learners of English. The learners completed a forced choice elicitation task and a written production task. The analysis revealed two misuse errors, namely the used in [+ specific, - definite] contexts interchangeably with $a$, the target article, 
and $a$ used in [-specific, + definite] contexts interchangeably with the target article the, as predicted by the $\mathrm{FH}$.

The formulation of the FH in Ionin et al. (2004) concerned only learners with [-article] L1s, in which case transfer of the Article Choice Parameter setting from the L1 is not possible. In order to test whether [+article] L1 learners fluctuate, it is necessary to compare L2 learners from various L1 backgrounds. In a follow-up study, Ionin et al. (in press), compared L2 learners whose L1 has articles (Spanish) with L2 learners from an article-less L1 (Russian) background. The participants in the study were 23 adult speakers of Russian and 24 adult speakers of Spanish. Ionin et al. (in press: 6) tested two competing hypotheses regarding the role of fluctuation and L1 transfer in the acquisition of articles.

5) a. Possibility 1: Fluctuation overrides transfer: all L2 learners should fluctuate between definiteness and specificity in their article choice. In other words, both Spanish and Russian learners are expected to misuse articles.

b. Possibility 2: Transfer overrides fluctuation: L2 learners whose L1s have articles should transfer article semantics from their L1 to their L2. The [-article] learners should fluctuate, since they have no parameter setting to transfer.

Ionin et al. (in press) found evidence supporting Possibility 2 . The results of a written elicitation test indicated that the Spanish learners of English transferred article semantics from their L1 to their L2, because they did not fluctuate between definiteness and specificity and distinguished between the and $a$ on the basis of definiteness. The Russian speakers, in the absence of L1 transfer, were less accurate than the Spanish speakers, as they fluctuated between distinguishing the and $a$ on the basis definiteness and on the basis of specificity, similar to the Russian speakers in Ionin et al. (2004).

Hawkins et al. (2006) also examined article use in adult L2 learners of English from [-article] Japanese and [+article] Greek backgrounds, and found corroborating evidence to support Ionin et al.'s (in press) contention that transfer overrides fluctuation. However, they offer a different analysis of what constitutes the nature of what is transferred. Specifically, they sought to explain transfer and interlanguage development at the level of feature assembly in the lexicon and insertion into the syntactic terminal nodes, rather than through a parameter-setting account. For instance, English L2 learners whose L1 grammars do not have features like $[+$ definite $]$ or $[-$ specific] assigned to lexical items like articles, 
must assemble the correct features with lexical forms in the L2 through direct access to UG and English input; L2 learners with [+article] L1s can do this more efficiently in their English L2 grammars.

As mentioned in Section I, a full investigation of the L2 acquisition of English articles by child learners has not yet been undertaken. Ionin $\mathrm{et} \mathrm{al}$. (in press: 21) expect child L2 'to converge on the definiteness pattern for English articles with greater success than adult L2-learners from the same L1', because young learners are better at making grammatical generalizations from variable input. Testing this prediction would require comparisons between child and adult learners with [-article] L1s in terms of rate and ultimate attainment in acquisition. Ionin et al. (in press) do not report straightforwardly how long their adult participants had been learning English and, in any case, the Russian L1 participants were a very heterogeneous group in terms of chronological age and age of arrival in the USA. Hawkins et al. (2006), Lardiere (2004) and White (2003), studied adults from [-article] backgrounds who had been learning English for over five years, and found that they had not yet converged. Furthermore, Hawkins et al.'s (2006) and Ionin et al. (in press) studies are cross-sectional, and while Ionin et al. (in press) divided their learners into proficiency groups, a longitudinal study design provides greater insights into how rapidly and successfully learner grammars converge on the target grammar. In sum, it is not known how rapidly a cohort of child L2 learners would need to reach mastery with English articles in order to distinguish themselves from adult learners. However, it is reasonable to assume that if they mastered this system in under five years of exposure, such an outcome would contrast with the existing findings for adults, and support Ionin et al.'s (in press) prediction.

Neither Ionin et al. (in press) nor Hawkins et al. (2006) focus their concern on infelicitous use of null articles. In Ionin et al. (2004) and Ionin et al. (in press), there were few cases of these errors. In Hawkins et al. (2006: 17), omission errors were produced by Japanese L1 learners in plural count noun contexts, but the authors do not highlight them in their discussion. It is possible that since both studies based their investigations of adult L2 learners' knowledge of article semantics through the (more formal) written mode, where learners had to fill in a blank with the, $a$ or zero, the rate of omissions would be expected to be low. In Lardiere's (2004) examination of a Chinese L1 - English L2 learner's use of articles, 
her article omissions in written contexts were less than half of her omissions in spontaneous oral speech (Lardiere, 2004: 331-32). Moreover, omission errors have been documented in numerous studies of English article acquisition. For instance, Huebner (1985), Parrish (1987), Robertson (2000) and White (2003) found a lot of use of the zero article in oral language.

The FH is formulated as an account of article misuse, not omission; however a feature-assembly based approach like that of Hawkins et al. (2006), or a Full Transfer/Full Access- (FT/FA) based account of functional structure and features (e.g. Schwartz and Sprouse, 1996) hold promise for incorporating both misuse and zero articles. Since both the FH and FT/FA share basic assumptions that L2 learners' already established L1 grammars, as well as UG accessed directly, play a role in determining L2 acquisition, these two approaches can be seen as mutually compatible. Put differently, FT/FA is a more general framework within which the FH could be situated. For this reason, we include FT/FA as a guide for predictions of acquisition patterns outside the realm of the FH. For example, following FT/FA, if there are no articles in a learner's L1, then that learner may produce infelicitous bare nouns, i.e. omit articles, in the initial state of L2 acquisition, because their initial L2 functional structure (coming from their L1) might not include a D projection, or the necessary semantic features assigned to lexical items like articles.

In addition to omission errors with articles, directionality in the kinds of misuse errors has also been documented in studies of adult L2 English. More specifically, it has been widely reported that L2 English learners are significantly more accurate in choosing the definite article in definite contexts than they are in choosing the indefinite article in indefinite contexts. Lardiere (2004), Robertson (2000) and White (2003) found this directional difference in accuracy in [-article] L1 learners. Interestingly, Anderson (1978) found the same difference in accuracy in Spanish learners of L2 English. Differential accuracy by context does not follow directly from the FH or FT/FA, but Ionin et al.'s (in press) and Hawkins et al.'s (2006) data show evidence for it (Ionin et al., in press: 10; Hawkins et al., 2006: 17). Lardiere (2004: 335) suggested that such differential accuracy could be due to the fact that 'definite articles in English need not take number and the count/mass distinction into account, which makes them less featurally complex than indefinites in at least one respect.' A similar conclusion can be drawn from Hawkins et al.'s (2006: 20) 
discussion of featural contexts of insertion for articles: $a$ is inserted in $[\mathrm{D},-$ definite, + singular $]$ contexts, the is inserted in $[\mathrm{D},+$ definite $]$ contexts. Thus, in order to use $a$ appropriately, learners have to identify the feature [singular] as relevant for the insertion of this article. If featural complexity is the underlying reason for this difference in accuracy of use between the and $a$, then L2 learners could be expected to display this pattern regardless of $\mathrm{L} 1$ background.

\section{The present study}

We examined longitudinal data from English L2 children from [+article] and [ - article] L1 backgrounds to address the following research questions:

1) Do both the $[+$ article $]$ and [ - article $]$ groups fluctuate between the two settings of the Article Choice Parameter? We expected [+article] L1 children to transfer the definiteness setting from their L1s and, thus, follow Ionin et al.'s (in press) Possibility 2: transfer overrides fluctuation. In contrast, the [-article] L1 children were expected to fluctuate between the definiteness and the specificity setting of the parameter. According to Ionin et al. (2004: 19), fluctuation results in two errors: the misuse in [ + specific, - definite] contexts and $a$ misuse in [-specific, + definite] contexts. Since in our task all contexts were $[+$ specific], we expected to find only the misuse errors, and only by the [-article] group.

2) Is the [-article] group more likely to omit articles than the [+article] group due to L1 transfer? Under Full Transfer, the [-article] L1 group, but not the [+article] L1 group, would be expected to omit articles because they do not have a D projection in their L1 that they can transfer to their L2. The [ + article] L1 group was not expected to omit articles, because they can transfer the DP structure from their L1.

3) Is there a difference between accuracy in article use in definite and indefinite contexts, and does this change as a function of L1 background? Since directionality in accuracy seems to be independent of L1 type, we expected both [ + article] and [ - article] L1 groups to be more accurate in using the in definite contexts than using $a$ in indefinite contexts.

4) Do both groups of these child L2 learners acquire English articles more rapidly and successfully than adult L2 learners? We expected 
these children would be able to achieve high, perhaps ceiling, levels of accuracy in article use within the time frame of the study, which would be considerably less than what has been reported for L2 adults. Nonetheless, the [-article] group was expected to be slower than the $[+$ article] group.

\section{Method}

a Participants: Seventeen children learning English as a L2 in Edmonton, Canada, were studied every six months for approximately 2 years. Children were from new Canadian families and had little or no exposure to English before regular attendance at a preschool or school program. Onset of exposure to English was determined by children's entry into such a program. The children's mean age was $5 ; 4$ and mean exposure to English was 9 months at the onset of the study. Ages and months of exposure for each child at the onset of testing are given in Table 1. At the second round of data collection, the children's mean age was $5 ; 10$, and mean months of exposure was 16 . At Round 3, mean age was $6 ; 4$, and mean months of exposure was 22 . At Round 4, mean age and months of exposure were $6 ; 10$ and 27 . At the final round, children's

Table 1 Children's L1, age at Round 1 of testing and months of exposure (MOE) to English

\begin{tabular}{|c|c|c|c|c|}
\hline Name & L1 & Type of L1 & Age & MOE \\
\hline LLKC & Arabic & {$[+$ article $]$} & $4 ; 10$ & 11 \\
\hline TRRK & Arabic & [+article $]$ & $4 ; 02$ & 8 \\
\hline YSSF & Arabic & {$[+$ article $]$} & $4 ; 11$ & 9 \\
\hline CHRS & Romanian & [+article] & $6 ; 02$ & 5 \\
\hline DVDC & Spanish & {$[+$ article $]$} & $6 ; 03$ & 8 \\
\hline SBST & Spanish & {$[+$ article $]$} & $5 ; 01$ & 15 \\
\hline SMNS & Spanish & {$[+$ article $]$} & $5 ; 07$ & 6 \\
\hline DNLN & Cantonese & {$[-$ article $]$} & $5 ; 02$ & 14 \\
\hline RNL & Cantonese & [-article] & $4 ; 08$ & 16 \\
\hline RMLM & Japanese & {$[$-article $]$} & $4 ; 02$ & 9 \\
\hline GSYN & Korean & [-article] & $5 ; 02$ & 2 \\
\hline DNNS & Mandarin/Cantonese & {$[$-article $]$} & $4 ; 07$ & 7 \\
\hline CNDX & Mandarin & {$[-$ article $]$} & $6 ; 09$ & 8 \\
\hline DNNC & Mandarin & [-article $]$ & $5 ; 09$ & 9 \\
\hline MRSS & Mandarin & {$[-$ article $]$} & $5 ; 00$ & 4 \\
\hline JHHN & Mandarin & [-article] & $5 ; 11$ & 18 \\
\hline TNYN & Mandarin & [-article] & $6 ; 07$ & 7 \\
\hline Mean & & & $5 ; 4$ & 9 \\
\hline
\end{tabular}


mean age was $7 ; 4$, and mean months of exposure was 34: almost three years.

These 17 children were part of a larger group of children participating in a longitudinal study of various aspects of English L2 development involving multiple measures of lexical, grammatical and narrative performance. For additional information about this study and these participants, see Paradis (2005) and Golberg et al. (2008). For the present study, 17 children were selected in order to form two groups, roughly equivalent in size, with [+article] and [-article] L1 backgrounds.

$b$ Determiners in the L1s of the children in this study: For the purposes of the present study, we distinguished a [+article] and a [ -article] L1 group on the basis of whether or not a learner's L1 has a grammaticalized way of expressing the feature of definiteness. As shown in Table 1, the [+article] L1 group includes children whose L1 is Spanish, Romanian and Arabic. The [-article] L1 group includes children whose L1s are Mandarin, Cantonese, Korean and Japanese. The system of articles in Spanish (Butt and Benjamin, 2000) is similar to the one described for English, because it groups articles on the basis of definiteness. Spanish has singular and plural definite masculine articles elllos and definite feminine articles lallas. Their indefinite counterparts are un and una. Similar to English and Spanish, Romanian (Mallinson, 1986) has definite and indefinite articles. Definite articles are attached to the end of the noun, while indefinite articles precede nouns. Arabic (Schulz, 2004) has a definite article $a l$ - or $l$-, which is prefixed to the noun, but there is no indefinite prefix. Instead, an $-n$ is added to case endings $-u,-i,-a$ to mark the indefiniteness of the noun (Schulz, 2004: 121), thus forming indefinite case endings - un, -in, -an, although this is only true of written Modern Standard Arabic; in spoken regional varieties of Arabic there is no audible indefinite article. Nevertheless, Arabic was also included in the [ + article] L1 group.

Mandarin, Cantonese, Korean and Japanese are different from all languages mentioned above, because they are all article-less languages (Matthews and Yip, 1994; Li and Thompson, 1997; Kuribara, 1999; Ionin, 2003: Chapter 3), even though they have other means of expressing semantic features like definiteness. In Mandarin, for instance, definiteness and indefiniteness can be marked by word order, the use of demonstrative 
pronouns $z h e i$ - 'this' and nei- or na- 'that' and the numeral yi- 'one' (Li and Thompson, 1997). The same is true for Cantonese (Matthews and Yip, 1994). Even though it might be argued that demonstratives and the numeral one present in L1s can be redeployed in L2 acquisition and facilitate the acquisition of articles, the English article system remains one of the most difficult language properties for speakers of such languages. Lardiere (2004: 331) noted that, instead of facilitating acquisition, such redeployment can further complicate it "by a kind of a "re-mapping" problem, in which Chinese speakers must further learn how to differentiate the forms one and that in English from the articles $a$ and the'. Furthermore, we reasoned that redeployment from a [-article] L1 would not facilitate article acquisition in the L2 in the same manner as L1 transfer in the case of a [+article] L1.

c Materials and procedures: We analysed the children's use of articles in narratives. The picture books used for the elicitation of narratives were designed as a part of the Edmonton Narrative Norms Instrument (ENNI) project (www.rehabmed.ualberta.ca/spa/enni). Each of the two picture books contained a set of three series of line drawings. Each series of drawings corresponded to a cohesive story, with the complexity of the stories increasing from the first series to the last. Elicitation was conducted by research assistants who were native speakers of Canadian English. Children were asked to tell the stories looking at the pictures, while the book was turned away from the experimenter and, thus, only visible to the child. This was done to ensure that the child could not resort to pointing and could not assume mutual speaker/hearer knowledge based on joint attention to the same picture. The experimenter had been instructed not to ask questions using the characters' names and to use neutral cues such as 'What happened?', 'Remember, I can't see the pictures'. All story elicitations were video-taped and transcribed by the experimenters in CHAT format (MacWhinney, 2000).

$d$ Data coding: The analysis was limited only to referring expressions that were used for the characters and concrete objects that were crucial for the storyline, i.e. four animate characters and three objects in each picture book. In order to have a uniform basis for comparing the use of articles 
across children, we did not include nouns used to give additional background information in the stories, such as sand, water, swimming pool, etc.

The narratives were analysed for instances of $a$, the and $\varnothing$ (null articles) used with nouns referring to new characters and nouns used to refer to these characters later on in the stories. For this study, we considered only the use of articles with common nouns. Other ways to refer to characters such as personal and deictic pronouns and proper names - were not included in the analysis. Thus, our analysis only included article use with singular common nouns. Two contexts of article use were set apart, namely indefinite contexts and definite contexts. Recall that Ionin et al. (2004) and Ionin et al. (in press) tested the use of $a$ and the in specific and non-specific contexts using a gap-filling task, in which the authors formulated sentences to get specific and non-specific readings of definites and indefinites. Since in our study the task was not a forced-choice elicitation task but a story-telling task, all the nouns in the stories were specific, under Ionin's (2003: 56) definition of specificity as 'speaker's intent to refer to an individual possessing a noteworthy property'. Therefore, signs of 'fluctuation' would consist of L2 learners of English misusing the in specific indefinite contexts.

Coding proceeded as follows. Articles used were coded according to their appropriateness in the context as 'correct $a$ ', 'incorrect the' (overuse) or 'null' in indefinite contexts, and 'correct the', 'incorrect $a$ ' (overuse) or 'null' in definite contexts. Null articles were always considered incorrect, since proper names were not included in the analysis. Consider the following examples of data coding:

6) incorrect the in indefinite context

*EXP: how do you start?

*CHI: \# mm \# the elephant throw the ball. (should be an elephant and a ball)

(JHHN 5;11)

7) correct $a$ in indefinite context

*CHI: and then uh the other rabbit called a ambulance. (meaning a doctor)

*EXP: an ambulance?

*CHI: yeah. and then um um grabbed his hand.

(SBST 7;01)

8) incorrect $\emptyset$ and correct the in definite context

${ }^{*} \mathrm{CHI}$ : so $\emptyset$ giraffe saw and called the lifeguard. (the is appropriate because the swimming pool and the diving board have been mentioned) (CNDX 8;09)

9) correct the in definite context

${ }^{*} \mathrm{CHI}$ : first there are two cross-eyed animals at the pool. 
*CHI: one was elephant $\ldots$ who had a very fat body.

*CHI: and the elephant, the female elephant was bouncing up and down her ball

(CNDX 8;09)

In data coding, it was also important to take into account the strategy that the children used in telling the story. Since the main characters were the same in the three stories in each picture book, some children told the three stories as one. In this case, only the first mentions of characters in the first story were coded as indefinite contexts. If some children started each of the three stories as an independent story, first mentions in each story were considered indefinite contexts.

\section{Results}

a Accuracy in the use of definite and indefinite articles: The questions we asked for the analyses in this section were as follows:

- Are accuracy rates higher with the in definite context than they are with a in indefinite context, and when does each reach over $90 \%$ ?

- Are the rates of acquisition different for children in the [-article] than in the [+article] L1 group?

Children's accuracy in indefinite contexts was calculated as a percentage of all obligatory contexts in which $a$ was supplied, obligatory contexts being singular nouns mentioned for the first time that were not proper nouns. Children's accuracy in definite contexts was calculated as a percentage of all obligatory contexts for the in which the was supplied. The resulting mean percentage correct use in context of $a$ and the for each round are shown in Figures 1 and 2, for the [+article] and [-article] L1 groups separately (bars in the graphs represent standard errors).

For both L1 groups, accuracy rates by context were consistently higher at all rounds with the than they were with $a$, and above $90 \%$ accuracy was reached at Round 3 for use of the in definite contexts by both groups. Above $90 \%$ accuracy with $a$ in indefinite contexts was reached at Round 4 by the [ + article] group and was not reached by the [-article] group at the end of the study. To further understand these observations we conducted a mixed ANOVA with L1 background as a between-participants factor ([+article] group and [-article] group) and round (5 levels) and article type (definite and indefinite) as within-participants factors. Both round 


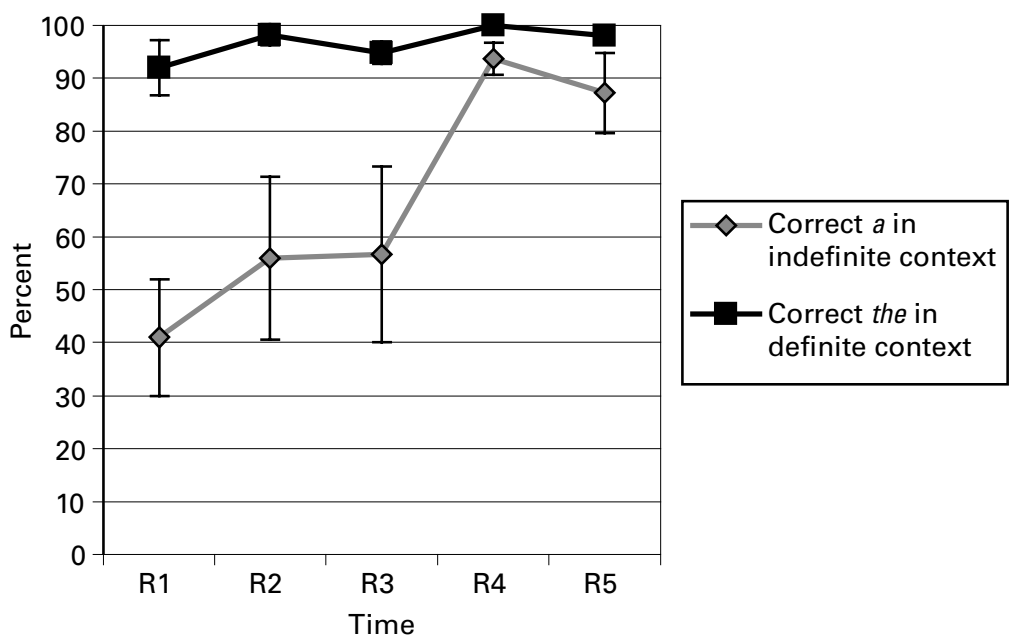

Figure 1 Mean percent correct use of articles for [+article] L1 Group

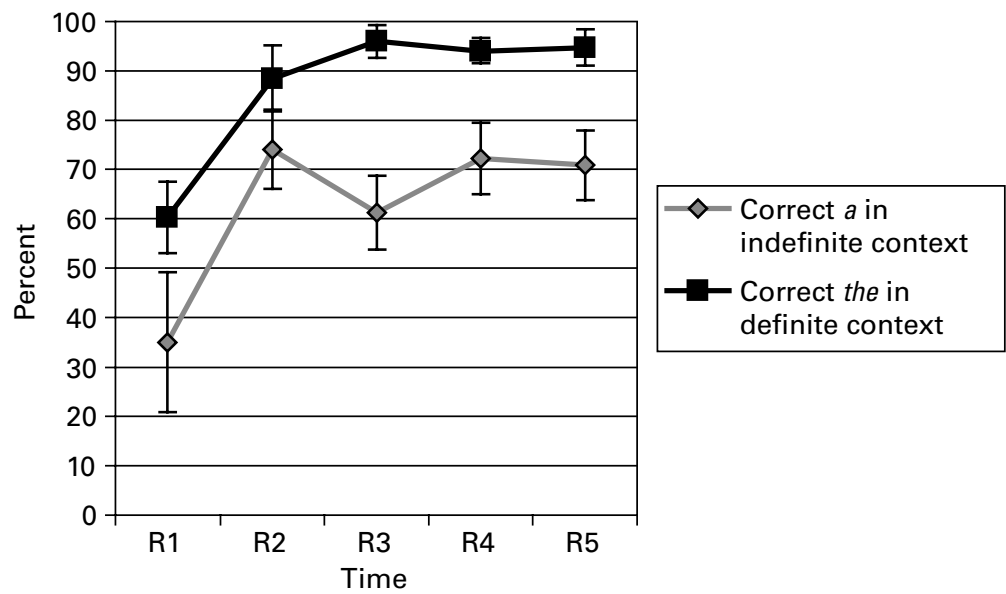

Figure 2 Mean percent correct use of articles for [-article] L1 Group

$(F(4,48)=10.68, p<.001$, partial eta squared $=.471)$ and article type $(F(1,12)=31.723, p<.001$, partial eta squared $=.726)$ main effects were significant, but L1 background was not $(F(1,12)=2.030, p=.180$, partial eta squared $=.145)$. Significant linear trends for both round $(F(1,12)=30.882, p<.001$, partial eta squared $=.720)$ and article type $(F(1,12)=31.723, p<.001$, partial eta squared $=.726)$ confirm that the 
learners grew steadily more accurate over time with their use of articles. The significant main effect for the two-level factor, article type, confirms that the children were more accurate with the definite than indefinite article, as the means for the former were consistently higher. The 3-way ANOVA yielded one significant interaction: round $\times$ article type $\times$ L1 background $(F(4,48)=2.914, p=.031$, partial eta squared $=.195)$. To further explore this interaction, we conducted post hoc independent sample pairwise $t$-tests on the correct use of each article type between each L1 group at each round. Applying a Bonferroni correction to the alpha level to control for Type I error $(\alpha=.005)$, we found just one significant result in all the pairwise comparisons: The [-article] group had lower accuracy with the definite article in context at Round 1 than the [+article group] $(60.2 \%$ vs. $92.2 \%, t(13)=-3.869, p=.002)$. We can conclude from this post hoc analysis that, overall, L1 background did not exert much influence on children's acquisition of articles, with the exception that the [-article] group were lagging behind in accuracy at Round 1 with the. Put differently, article type was a more important factor than L1 background in acquisition patterns and rates. Children in both groups were more accurate with the in definite contexts than with $a$ in indefinite contexts throughout the two-year period of observation, and acquired the use of the in definite contexts by Round 3 .

An analysis of individual scores confirmed that the majority of children followed the group trend. Individual accuracy scores are given in Appendix 1, in which we collapsed the scores across the five rounds, because entering individual scores for each child at each round would make the tables too numerous. We can see that 15 out of 17 children were more accurate with article choice in definite than in indefinite contexts. The two children that did not conform to the general trend, CNDX and RMLM, both belong to the [-article] L1 group.

$b$ Error type distribution in definite and indefinite contexts: The questions we asked for the analyses in this section were:

- What is the relative distribution of the misuse, $a$ misuse and article omission among children's errors?

- Is the misuse the most common error? 
- Does L1 background interact with error types, for example, do the [-article] children have more article omissions than the [+article] children?

The frequencies of error types per child per round varied such that in some cases they were less than 2 . Therefore, analyses in this section were designed such that percentages per child, per round were not calculated on the grounds that they could be unreliable. First, the proportion of incorrect use of the, $a$ and null articles was calculated from the total number of errors at each round across all children, and divided by L1 group and by definite and indefinite context. There were four possible types of errors: the in indefinite context, $a$ in definite context, null article in indefinite context, and null article in definite context. (Recall that null articles in this story-telling task would always be errors, even though in many semantic contexts in English, null articles are a grammatical choice.) The results of these analyses are presented in Figures 3 and 4.

The results demonstrate that the misuse was clearly the dominant error type for both the [+article] and [-article] groups, and that null articles were an error type specific to the [-article] group, since they were negligible in the [+article] group data but appeared in the [-article] group data in both definite and indefinite contexts. Furthermore, null articles began to disappear even for the [-article] group after Round 2, indicating that these errors were more frequent during the early stages of these children's English L2 acquisition.

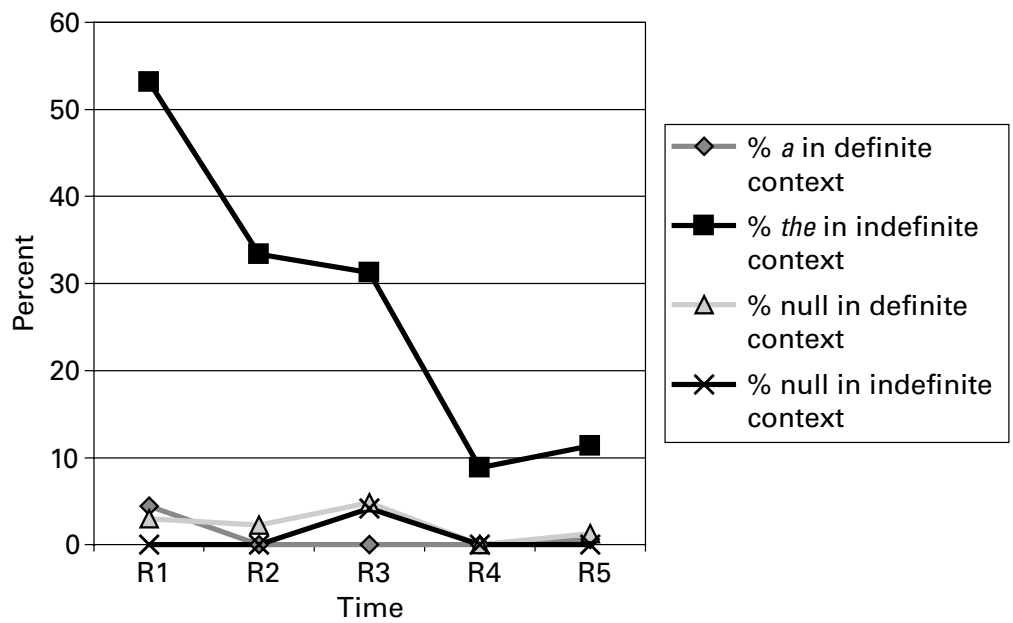

Figure 3 Percent distribution of error types for [+article] L1 Group 


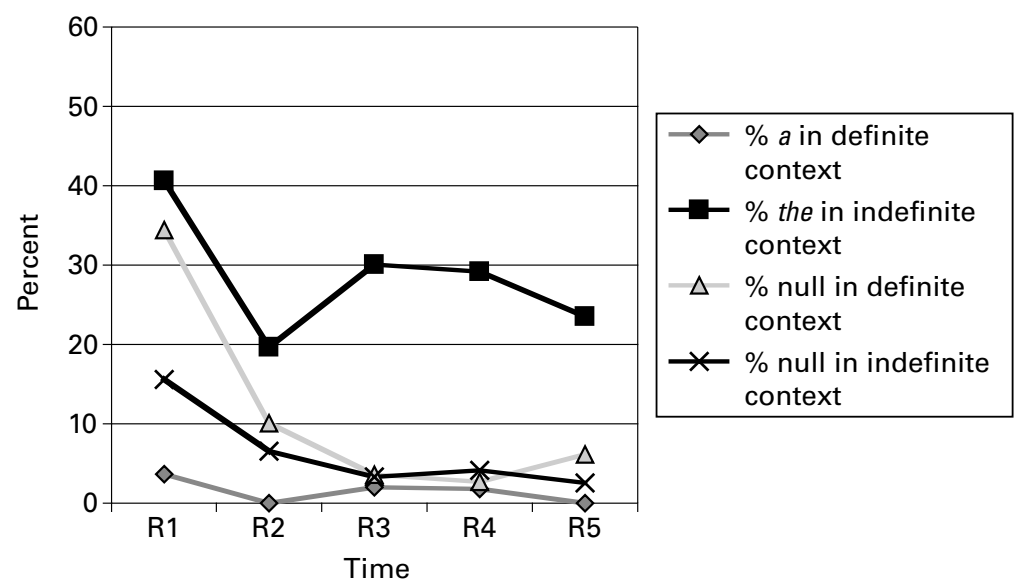

Figure 4 Percent distribution of error types for [-article] L1 Group

To complement this distributional analysis, we conducted independent sample $t$-tests on children's mean proportion of the different error types across all rounds, divided by context and L1 group. The mean proportions of incorrect $a$ and null articles in definite contexts - and incorrect the and null articles in indefinite contexts - for the [ + article] and [-article] L1 groups are given in Table 2, with the results of the $t$-tests. The $t$-test analysis supports the distributional data in Figures 3 and 4: the only significant group differences are for null article use in definite and indefinite contexts, with the [-article] children having a higher proportion of these errors.

A comparison of individual scores for article substitution errors and omission errors in definite and indefinite contexts (see Appendix 2) revealed that the misuse was indeed the predominant error in all [+article] L1 learners and in eight out of nine [-article] L1 learners. As for null articles, individual data demonstrate that article omission was a common error in the [-article] L1 group, but not in the [+article] L1 group. Only three children did not follow the general trend of their L1 group with respect to omissions: JNNH and DNNC omitted fewer articles than other children in the [-article] L1 group (in 1.8\% and 1.3\% of contexts, respectively), and TRRK omitted more than other children in the [ + article] group (in 5.3\% of contexts).

\section{Discussion}

The primary goal of this study was to test predictions from the $\mathrm{FH}$ and the FT/FA account for the acquisition of English articles by children 
Table 2 Mean proportions of error types by group

\begin{tabular}{|c|c|c|c|}
\hline L1 Group & Mean & $t$-value & $p$-value \\
\hline $\begin{array}{l}\text { Incorrect a in definite context: } \\
{[- \text { article }]} \\
{[+ \text { article }]}\end{array}$ & $\begin{array}{l}.013 \\
.010\end{array}$ & $t(15)=0.477$ & $p=.641$ \\
\hline $\begin{array}{l}\text { Null article in definite context: } \\
{[- \text { article }]} \\
{[+ \text { article }]}\end{array}$ & $\begin{array}{l}.088 \\
.029\end{array}$ & $t(15)=2.375$ & $p=.036^{*}$ \\
\hline $\begin{array}{l}\text { Incorrect the in indefinite context: } \\
{[- \text { article }]} \\
{[+ \text { article }]}\end{array}$ & $\begin{array}{l}.281 \\
.249\end{array}$ & $t(15)=0.459$ & $p=.653$ \\
\hline $\begin{array}{l}\text { Null article in indefinite context: } \\
{[- \text { article }]} \\
{[+ \text { article }]}\end{array}$ & $\begin{array}{l}.035 \\
.009\end{array}$ & $t(15)=2.638$ & $p=.019^{*}$ \\
\hline
\end{tabular}

from L1 backgrounds with and without articles. We also wanted to see whether there was a difference between children's accuracy in article use in definite and indefinite contexts, and whether it changed as a function of L1 background. Finally, we wanted to investigate whether these child L2 learners converged on the target grammar more rapidly and successfully than adult L2 learners. In the sections below we discuss the predictions put forward in Section I.3 together with the relevant findings from this study.

\section{Fluctuation, transfer and article (mis)use}

We expected [+article] L1 children to transfer the definiteness setting from their L1s, and [ - article] L1 children were expected to fluctuate, i.e. sometimes misuse the in specific indefinite contexts. Contrary to our expectations, we found that both L1 groups had the misuse errors in indefinite contexts, and that L1 background was not associated with differential accuracy rates for article use over time, except to a limited extent at Round 1. In other words, all learners demonstrated a fluctuation pattern in their article choice, and little L1 influence. So, in Ionin et al.'s (in press) terms, for these L2 learners with [+article] L1s, fluctuation overrode L1 transfer instead of the other way around. This finding is perhaps not surprising in consideration of potential differences between child and adult L2 acquisition. For young L2 learners, it is conceivable that access to Universal Grammar to establish a new, language-specific grammar for the target input could be more efficient than it is for older 
L2 learners who rely more on transfer from their L1 for a longer period of time. Other studies of child L2 morphosyntactic acquisition have also found that L1 transfer seems to be less pronounced than in adult L2 acquisition (for review, see Paradis, 2007).

\section{Article omission}

Under Full Transfer, the [-article] L1 group, but not the [+article] L1 group, was expected to omit articles. As predicted, the [ - article] L1 group had null article errors early on, while the [+article] L1 group did not. A possible interpretation of this difference is that the absence of the category $D$ in the initial state grammars of the [-article] group was reflected in their omission errors in language production. However, our discussion above regarding the FH contradicts the idea of Full Transfer, because [+article] L1 learners did not seem to transfer the definiteness setting of the Article Choice Parameter from their L1. We assume that learners in both groups had access to the inventory of semantic features, such as $[+/-$ definite $]$ and $[+/-$ specific], as well the inventory of functional projections including $\mathrm{D}$, from Universal Grammar. Perhaps at the outset of acquisition, the L2 learners from [+article] L1 backgrounds transferred the knowledge of the category D from their L1 functional structure, but did not necessarily transfer the grouping of semantic features from their lexicons. It is possible that Full Access to parameter (re)setting and/or semantic features in Universal Grammar takes precedence over Full Transfer of semantic feature groups from the L1 lexicon, while Full Transfer of functional structure takes precedence over instantiation of new functional projections, through Full Access to Universal Grammar, in the L2 initial state. Further research is needed to better understand whether Full Access to Universal Grammar and Full Transfer from the L1 may override one another depending on the aspect of language concerned.

\section{Accuracy in indefinite and definite contexts}

We expected both the [+article] and [-article] L1 groups to be more accurate with the in definite contexts than with $a$ in indefinite contexts. As predicted, we found that the target article was used more often in definite contexts than in indefinite contexts. This difference was present at all stages of acquisition, and across learners with different L1 
backgrounds and, thus, was a robust pattern. Since the same pattern has been found in previous research on adult L2 acquisition, this pattern could be a general property of English L2 acquisition, possibly due to the greater semantic complexity of $a$, as discussed in Lardiere $(2004 ; 2005)$ and Hawkins et al. (2006). Therefore, the inherent complexity of this target form seemed to trump L1 transfer in that no between-group differences emerged at any time in the observation period with respect to the higher accuracy levels in the use of articles in definite vs. indefinite contexts.

\section{The rate of acquisition and convergence}

We expected these child learners to achieve a high level of accuracy in article use by the end of the study, with the [-article] children being slower due to the absence of facilitative transfer of the category D from their L1s. We found evidence supporting the first part of this expectation since accuracy levels in context of $90 \%$ or higher were achieved early on for the by both groups, and for $a$ at Round 4 by the [+article] group. Comparing the results from child L2 learners in our study and adult learners of L2 English in previous studies, we can conclude that the child learners certainly converged faster. For instance, Hawkins et al. (2006: 17) reported 50-58\% the misuse in the advanced Japanese group whereas, for the children in our study, at Round 5 (34 months of exposure) there was about $10 \%$ the misuse in the [+article] group and about $20 \%$ the misuse in the [-article] group and, in any case, no significant between-group differences emerged at Round 5. Regarding the predicted slower development of the [-article] group, the lower accuracy with the in definite context at Round 1, and the absence of ceiling scores for use of $a$ in indefinite context by the end of the study, suggest that the $[-$ article] group displayed slower acquisition rates, but only to a limited extent.

\section{Conclusions}

This study revealed similarities and dissimilarities between child and adult L2 acquisition of the English article system. On the one hand, both adult and child learners' acquisition patterns were influenced by the greater inherent complexity of the indefinite article in English, and omission errors were most commonly produced by learners whose L1s lacked 
articles. On the other hand, overall we found a more limited role of L1 influence in the children's developmental patterns and rates of article acquisition, compared with previous work on adult $\mathrm{L} 2$ acquisition of articles. More specifically, we found that these children showed the opposite pattern, vis à vis fluctuation and transfer, than the L 2 adults studied by Ionin et al. (in press), and that child L2 learners converged on the target system faster than prior reports have indicated for adult L2 learners, even when their L1s lack articles.

\section{References}

Anderson, J. 1978: Order of difficulty in adult second language acquisition. In Ritchie, W., editor, Second Language Acquisition Research: Issues and implications. London: Academic Press, 91-108.

Butt, J. and Benjamin, C. 2000: A new reference grammar of modern Spanish. London, Arnold.

Dulay, H.S. and Burt, M.K. 1974: Natural sequences in child second language acquisition. Language Learning 24, 37-53.

Golberg, H., Paradis J. and Crago, M. 2008: Lexical acquisition over time in L1 minority children learning English as a second language. Applied Psycholinguistics 29.

Hawkins, R., Al-Eid, S., Almahboob, I., Athanasopoulos, P., Chaengchenkit, R., Hu, J., Rezai, M., Jaensch, Carol., Jeon, Y., Jiang, A., Leung, Y.-K.I., Matsunaga, K., Ortega, M., Sarko, G., Snape, N. and VelascoZárate, K. 2006: Accounting for English article interpretation by L2 speakers. In Foster-Cohen, S.H., Medved Krajnovic, M. and Mihaljević Djigunović, J., editors, EUROSLA Yearbook: Volume 6, pp. 7-25.

Haznedar, B. 2001: The acquisition of the IP system in child L2 English. Studies in Second Language Acquisition 23, 1-39.

Huebner, T. 1985: System and variability in interlanguage syntax. Language Learning 35, 141-63.

Ionin, T. 2003: Article Semantics in Second Language Acquisition. Unpublished doctoral dissertation, MIT.

Ionin, T. and Wexler, K. 2003: The certain uses of the in L2-English. In J.M. Liceras et al., editors, Proceedings of the 6th Generative Approaches to Second Language Acquisition Conference. Cascadilla Press, 150-60.

Ionin, T., Ko, H. and Wexler, K. 2004: Article semantics in L2 acquisition: The role of specificity. Language Acquisition 12, 3-69.

Ionin, T., Zubizarreta, M.L. and Maldonado, S.B. in press: Sources of linguistic knowledge in the second language acquisition of English articles. Lingua. Retrieved from https://netfiles.uiuc.edu/tionin/www/(November 2007). 
Johnson, J. and Newport, E. 1989: Critical period effects in second language learning: the influence of maturational age on the acquisition of English as a second language. Cognitive Psychology: 21, 60-99.

Kuribara, C. 1999: Resettability of a syntactic parameter: acquisition of category D in English by adult Japanese speakers. Representation and process: proceedings of the 3rd Pacific Second Language Research Forum. Tokyo: PacSLRF'99, 13-22.

Lakshmanan, U. 1995: Child second language acquisition of syntax. Studies in Second Language Acquisition 17, 229-301.

Lardiere, D. 2004: Knowledge of definiteness despite variable article omission. In Brugos, A., Micciulla, L. and Smith, C.E., editors, BUCLD 28 Proceedings. Somerville, MA: Cascadilla Press, 328-39.

— 2005: On morphological competence. In Dekydspotter, L., Sprouse, R.A. and Liljestrand, A., editors, Proceedings of the 7th Generative Approaches to Second Language Acquisition Conference (GASLA 2004). Somerville, MA: Cascadilla Proceedings Project, 178-92.

Li, Ch. and Thompson, S. 1997: Mandarin Chinese: a functional reference grammar. Taipei: Crane Publishing.

Lu, C.F.-C. 2001: The acquisition of English articles by Chinese learners. Second Language Studies 20, 43-78.

Lyons, C. 1999: Definiteness. Cambridge: Cambridge University Press.

MacWhinney, B. 2000: The CHILDES project: tools for analyzing talk. 3rd edition. Mahwah, NJ: Erlbaum.

Mallinson, G. 1986: Rumanian. London: Croom Helm.

Master, P. 1987: A cross-linguistic interlanguage analysis of the acquisition of the English article system. Unpublished doctoral dissertation, UCLA.

Matthews, S. and Yip, V. 1994: Cantonese: a comprehensive grammar. Routledge: London and New York.

Murphy, S. 1997: Knowledge and production of English articles by advanced second language learners. Unpublished doctoral dissertation, University of Texas at Austin.

Paradis, J. 2005: Grammatical morphology in children learning English as a second language: implications of similarities with specific language impairment. Language, Speech and Hearing Services in the Schools 36, 172-87.

2007: Second language acquisition in childhood. In Hoff, E. and Shatz, M., editors, Handbook of language development. Oxford: Blackwell, 387-406.

Parrish, B. 1987: A new look at methodologies in the study of article acquisition for learners of ESL. Language Learning 37, 361-83.

Robertson, D. 2000: Variability in the use of the English article system by Chinese learners of English. Second Language Research 16, 135-72.

Schulz, E. 2004: A student grammar of modern standard Arabic. Cambridge: Cambridge University Press. 
Schwartz, B. 2004: Why child L2 acquisition? In Van Kampen, J. and S. Baauw, editors, Proceedings of Generative Approaches to Language Acquisition Conference 2003. LOT Occasional Series 3, 47-66.

Schwartz, B. and Sprouse, R. 1996: L2 cognitive states and Full Transfer/Full Access model. Second Language Research 12, 40-72.

Snape, N., Leung, I.-K. and Ting, H.-C. 2006: Comparing Chinese, Japanese and Spanish speakers in L2 English article acquisition: evidence against the fluctuation hypothesis? In Grantham O'Brien, M., Shea, C. and Archibald, J., editors, Proceedings of the 8th Generative Approaches to Second Language Acquisition Conference (GASLA 2006). Somerville, MA: Cascadilla Proceedings Project, 132-39.

Thomas, M. 1989: The acquisition of English articles by first- and secondlanguage learners of English. Applied Psycholinguistics 10, 335-55.

Trademan, J. 2002: The acquisition of the English article system by native speakers of Spanish and Japanese: a cross-linguistic comparison. Unpublished $\mathrm{PhD}$ dissertation, University of New Mexico.

Wakabayashi, S. 1997: The acquisition of functional categories by learners of English. Unpublished doctoral dissertation, University of Cambridge.

White, L. 2003: Fossilization in steady state L2 grammars: implications of persistent problems with inflectional morphology. Bilingualism: Language and Cognition 6, 128-41.

Appendix 1 Percent suppliance of articles in target contexts, collapsed across all rounds

\begin{tabular}{lccc}
\hline Name & {$[+$ /-article] L1 } & $\begin{array}{l}\text { Correct } a \text { in indefinite } \\
\text { contexts }\end{array}$ & $\begin{array}{c}\text { Correct the in definite } \\
\text { contexts }\end{array}$ \\
\hline CHRS & + & 87.9 & 97.4 \\
DVDC & + & 84.4 & 95.9 \\
LLKC & + & 48.1 & 100.0 \\
SBST & + & 84.2 & 95.2 \\
SMNS & + & 65.4 & 99.1 \\
TRRK & + & 69.2 & 91.8 \\
YSSF & + & 74.4 & 93.9 \\
CNDX & - & 78.8 & 76.5 \\
DNLN & - & 56.7 & 97.5 \\
DNNC & - & 79.4 & 98.4 \\
DNNS & - & 86.0 & 94.6 \\
GSYN & - & 69.2 & 85.9 \\
JNNH & - & 44.4 & 97.1 \\
MRSS & - & 52.2 & 89.3 \\
RMLM & - & 76.9 & 76.3 \\
RNLX & - & 60.0 & 88.1 \\
TNYN & - & 71.4 & 94.8 \\
\hline
\end{tabular}


Appendix 2 Percent misuse of $a$ in definite contexts, the in indefinite contexts, and article omissions in both contexts, collapsed across all rounds

\begin{tabular}{llllc}
\hline ID & {$[+/-$ article] L1 } & $\begin{array}{l}a \text { in definite } \\
\text { contexts }\end{array}$ & $\begin{array}{l}\text { the in indefinite } \\
\text { contexts }\end{array}$ & Omission \\
\hline CHRS & + & 1.8 & 12.1 & 0.7 \\
DVDC & + & 0.0 & 15.6 & 2.5 \\
LLKC & + & 0.0 & 51.9 & 0.0 \\
SBST & + & 0.0 & 15.8 & 3.0 \\
SMNS & + & 0.0 & 27.8 & 0.5 \\
TRRK & + & 2.0 & 26.9 & 5.3 \\
YSSF & + & 3.0 & 23.3 & 2.6 \\
CNDX & - & 1.0 & 12.1 & 20.5 \\
DNLN & - & 0.0 & 40.0 & 7.1 \\
DNNC & - & 0.0 & 20.6 & 4.3 \\
DNNS & - & 0.8 & 9.3 & 19.0 \\
GSYN & - & 1.2 & 28.2 & 1.8 \\
JHHN & - & 1.4 & 51.9 & 7.9 \\
MRSS & - & 1.0 & 47.8 & 7.7 \\
RMLM & - & 3.7 & 7.7 & 7.1 \\
RNLX & - & 3.4 & 36.0 & 4.3 \\
TNYN & - & 0.7 & 25.0 & \\
\hline
\end{tabular}

